\title{
Effect of anisotropy on the deep-drawing of mild steel and dual-phase steel tailor-welded blanks
}

\author{
R. Padmanabhan*, A.J. Baptista, M.C. Oliveira, L.F. Menezes \\ CEMUC, Department of Mechanical Engineering, University of Coimbra, Polo II, Pinhal de Marrocos, 3030-201 Coimbra, Portugal \\ Received 19 July 2006; received in revised form 22 November 2006; accepted 22 November 2006
}

\begin{abstract}
Tailor-welded blanks made of dissimilar, uniform or non-uniform thickness materials have potential applications in automobile industries. Compared to the base metal, the formability of tailor-welded blank is less due to the presence of weld area and strength mismatch between component blanks. Most sheet metals used to produce tailor-welded blanks have anisotropy induced during pre-processing stage due to large deformation. The orientation of the blank sheet rolling direction and the combination of the blank sheet materials has significant influence on the deformation behaviour. The effect of anisotropy in the tailor-welded blank and the orientation of blank sheets rolling direction during deep-drawing process are investigated in this study. Finite element analysis of deep-drawing mild steel and dual-phase steel tailor-welded blank models was carried out using research purpose FE code DD3IMP; to form a basis for tailor-welded blank design and development for a part. Anisotropy in the blank sheets has moderate influence and its contribution to increased material flow depends on the mechanical properties of the blank sheets. Appropriate combination of the blank sheets rolling direction orientation can significantly improve the formability of the tailor-welded blank in the deep-drawing of square cup.
\end{abstract}

(C) 2006 Elsevier B.V. All rights reserved.

Keywords: Tailor-welded blank; Anisotropy; DD3IMP; Deep-drawing; Finite element analysis

\section{Introduction}

Environmental concern and fast depletion of fossil fuels have forced automobile manufacturers to implement strict government environmental regulations and to cater increased customer demands for improved fuel efficiency. Thus, the automobile industries are driven to look for high performance and light weight materials in order to improve the fuel efficiency, aesthetic and reduce the cost of the vehicle. One way of handling this issue is to increase the application of tailor-welded blanks in the automobile body parts. Through proper location of apt material in the automobile body by tailor-welding, the required functions of the body part can be accomplished at nominal cost. Tailorwelded blanks are produced from combination of materials brought together by employing advanced welding techniques, such as laser beam, mash-seam or electron beam welding. These techniques are intended to produce narrow weld-line with least heat-affected zone. Tailor-welded blanks thus produced with dis-

\footnotetext{
* Corresponding author. Tel.: +351 239790715; fax: +351 239790700.

E-mail address: padmanabhan@dem.uc.pt (R. Padmanabhan).
}

similar and uniform or non-uniform thickness materials can be subjected to deformation to produce automobile components, such as body side panels, motor compartment rails, center pillar inner panels, wheelhouse/shock tower panels [1-4] and other market areas [5]. The formability of tailor-welded blanks is significantly affected by the location and orientation of the weldline [6-8]. The strength and thickness mismatch between the monolithic sheet materials produces complex stress state in the tailor-welded blank during deep-drawing. The stronger material in the tailor-welded blank will resist deformation more than the weaker material, causing the weld-line to move in the deep drawn part. A number of attempts have been made to modify the traditional forming process to improve the formability of tailor-welded blanks $[3,6]$. The weld-line movement during deep-drawing can be restricted by applying differential blankholder force or by using a draw bead [6,7].

The material flow during the deep-drawing process is also affected by the blank sheet anisotropy. Anisotropy in blank sheets is usually the result of a large deformation during initial processing operations such a rolling, extrusion, etc. This anisotropy prevalent in the pre-processed sheet segment influences subsequent deformation, such as deep-drawing. It dictates 
the shape of the yield surface and strongly affects the strain distributions obtained during sheet metal forming [9]. Finite element simulations of metal forming provide an effective means to investigate the relationship between processing deformation and structure of the material, and therefore, useful guidance in fine-tuning production processes. In addition, the formability and failure patterns of tailor-welded blanks can be accurately predicted with appropriate draw restraining forces and material properties. Application of finite element methods to deep-drawing analysis, with the aim to better understand the forming processes, enables precise designing of tailor-welded sheet metal parts, the tools and the forming processes $[6-8,10]$. Many studies have been undertaken to determine the formability of tailor-welded blanks using standard tests, such as free bend test, stretch bend test, Limit Dome Height test, both experimentally and through simulation $[10,11]$. However, very little information is available regarding the effect of anisotropy under complex stress-strain states, such as that occurs, for example, in a square cup deep-drawing process. The present investigation is focussed on the numerical evaluation of the effect of anisotropy and the rolling direction orientation on the forming behaviour of mild steel and dual-phase steel tailor-welded blank. Static implicit finite element code DD3IMP was used to perform the simulations. Modelling and simulation of tailor-welded blank forming is described in Section 2. Discussion on the simulation results is presented in Section 3. Based on the results and discussion, conclusions are drawn in Section 4.

\section{Modelling and simulation}

\subsection{Finite element model}

The finite element method is one of the most effective approaches to simulate and evaluate deep-drawing process, to obtain the optimal design and minimize material and time in experimentation. The knowledge acquired from finite element analysis can be used in the design and development of tailorwelded blank for a part. DD3IMP FE code is a unique freeware open-source lab-code with proven reliability in the testing of new solutions in the field of computational mechanics applied to sheet metal forming. Several advanced constitutive models and work-hardening laws can be implemented in the FE code. The present problem is the classical Numisheet'93 Square cup deep-drawing [12]. The numerical simulation tools consist of a die, a punch and a blank holder as shown in Fig. 1.

The deep-drawing process simulation is accomplished in three phases:

(i) the blank holder is moved to apply a predetermined holding force on the tailor-welded blank;

(ii) the punch is moved to a predetermined depth;

(iii) both the punch and the blank holder are removed from the deep-drawn tailor-welded blank to perform one step springback.

Finite element models of mild steel (DC06) and dual-phase steel (DP600) tailor-welded blanks were considered excluding

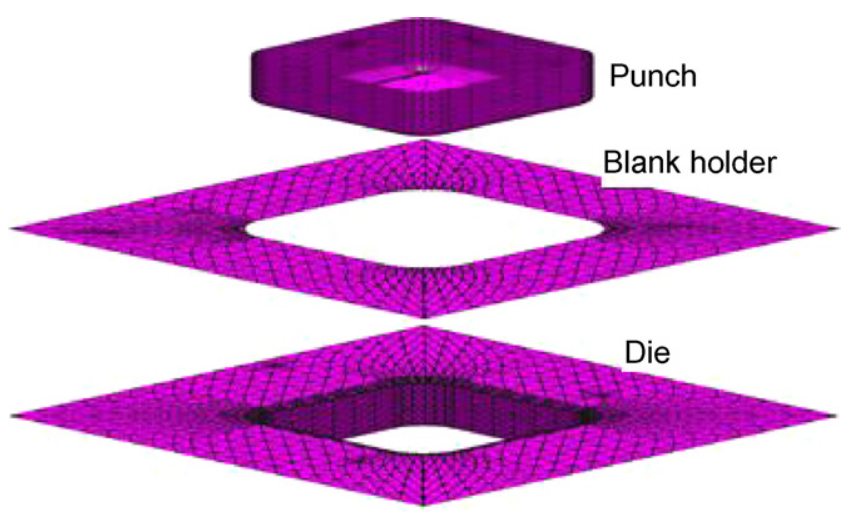

Fig. 1. Tools used in finite element simulations.

weld region [13] due to small weld area compared to large tailor-welded blank surface area. Weld-line displacement is an important indicator of overall deformation pattern of the tailor-welded blank. It is determined by the properties of the component blank sheets and the restraining forces with little influence of local friction or local weld properties [14]. Since the effect of local weld properties on the finite element simulation results is insignificant $[4,6,10,15]$, and the focus is to study the effect of anisotropy on the deep-drawing process, the weld-line is excluded in the tailor-welded blank for this study. The two materials chosen for this study are widely used in automobile body parts manufacture and were extensively characterized [16]. Considering the geometric and material symmetry, a half-square tailor-welded blank geometry was used in the simulations, Fig. 2(a). The initial thickness of the blank sheet segments in the tailor-welded blank is $1 \mathrm{~mm}$. In order to

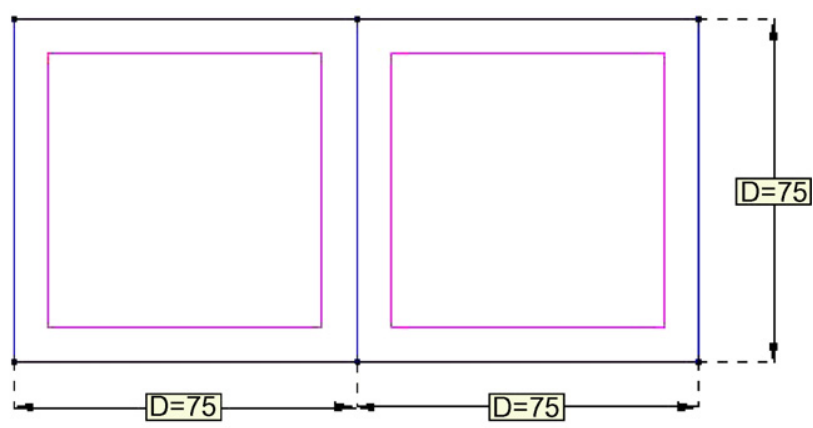

(a)

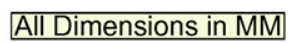

y

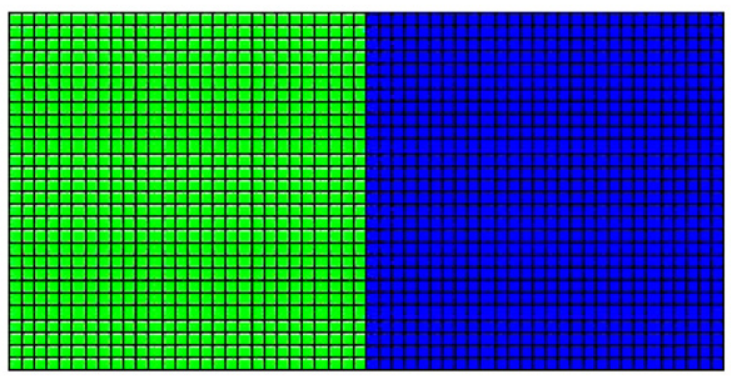

(b) DC06

DP600

Fig. 2. (a) Tailor-welded blank geometry and (b) finite element mesh. 
obtain a practical solution, detailed information on the deepdrawing process parameters and the blank materials is required for the finite element simulation. The accuracy of the computed results depends on the selection made regarding various modelling parameters. The optimal process parameters were arrived after running few test simulations. During these simulations, several meshes with eight node 3D solid finite elements were considered for the tailor-welded blank to obtain better relation between accuracy of the results and computing time. In-plane mean mesh size of approximately $2.5 \mathrm{~mm}$ was used with two layers through thickness. This allows correct calculation of the stress and strain gradients through thickness as well as the thickness evolution over the entire deep-drawing simulation. Thus, a mesh of 3136 elements and 4959 nodes was employed in the simulations, Fig. 2(b). The tailor-welded blank finite element model was created using GID software [17].

\subsection{Deformation behaviour of blank sheet materials}

The elastic behaviour of both DC06 and DP600 steel blank sheets are considered isotropic. The work-hardening behaviour of the two materials is considered isotropic and described by Swift's power-type law of Eq. (1):

$\bar{\sigma}=K\left(\varepsilon_{0}+\bar{\varepsilon}^{\mathrm{P}}\right)^{n}$

where $\bar{\sigma}$ is the equivalent tensile stress, $\bar{\varepsilon}^{\mathrm{P}}$ the equivalent plastic strain and $\varepsilon_{0}, K, n$ are material parameters identified by mechanical tests. The plastic anisotropy is described by a yield criterion that defines the shape of the yield locus.

A good description of the anisotropy in the rolled sheets is essential for a quantitative approach to deep-drawing process simulations. Phenomenological plasticity theories consider initial anisotropy through a yield criterion. A number of such yield criterions has so far been proposed by Hill [18], Barlat et al. [19,20], Karafillis and Boyce [21], Drucker [22], etc., and equally studies have been carried out to compare these yield functions, for instance [23-27]. Hill'48 yield function is widely used in finite element simulation studies and has been very useful for explaining some phenomena associated with anisotropic plasticity. Hence, in this work, the anisotropy of the rolled sheet segments in the tailor-welded blank is described by the analytical function in the quadratic form postulated by Hill:

$$
\begin{aligned}
\bar{\sigma}^{2}= & F\left(\sigma_{22}-\sigma_{33}\right)^{2}+G\left(\sigma_{33}-\sigma_{11}\right)^{2}+H\left(\sigma_{11}-\sigma_{22}\right)^{2} \\
& +2 L \sigma_{23}^{2}+2 M \sigma_{31}^{2}+2 N \sigma_{12}^{2}
\end{aligned}
$$

where the numerals 1,2 and 3 stand for the orthotropic directions. $F, G, H, L, M$ and $N$ are the six material parameters that depend on the flow stresses under uniaxial and shear loading

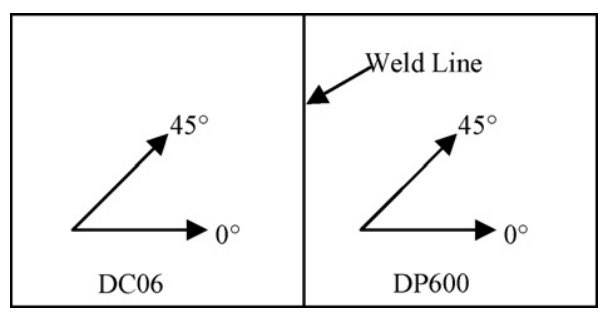

Fig. 3. Rolling direction orientation of blank sheets with respect to the weld-line.

in the principal directions, respectively, and implicitly assumes that hydrostatic stress states lead to no yielding and no plastic deformation. These parameters are calculated from the $r$-ratios $r_{0}, r_{45}$ and $r_{90}$, which are the ratios of the width-to-thickness strains during a tensile test, at $0^{\circ}, 45^{\circ}$ and $90^{\circ}$, respectively, to the rolling direction. DP600 is nearly isotropic regarding the flow stress $\left(r_{0}=1.01, r_{45}=0.76\right.$ and $\left.r_{90}=0.98\right)$ and DC06 exhibits a weak planar anisotropy of the flow stress $\left(r_{0}=2.53, r_{45}=1.84\right.$ and $r_{90}=2.72$ ). The material properties of DC06 and DP600 segments of the tailor-welded blank used in the simulation are listed in Table 1 [16].

The contact between the rigid tools and the blank sheet segments is solved using the classic Coulomb model. A constant friction coefficient $(\mu)$ of 0.144 was used.

As shown in Fig. 3, two different orientations, viz. $0^{\circ}$ and $45^{\circ}$ of the rolling direction of the blank sheets with respect to the weld-line was implemented.

\subsection{Numerical simulation}

Drawing simulations were carried out using the in-house finite element code DD3IMP (contraction of deep-drawing 3d IMPlicit code). DD3IMP is specifically developed to simulate sheet metal forming processes. The evolution of the deformation process is described by an updated Lagrangian scheme. An explicit approach is used to calculate an approximate first solution for the nodal displacements, the stress states and frictional contact forces. This first trial solution of the configuration and state of the deformable body is therefore iteratively corrected. This correction phase is done implicitly using a Newton-Raphson algorithm and finishes when a satisfactory equilibrium of the deformable body is achieved. It is then possible to update the blank sheet configuration at the end of time increment, as well as all the state variables, passing on to the calculation of the next increment until the end of the process [28].

In sheet metal forming processes, the boundary conditions are dictated by the contact established between the blank sheet and tools. Such boundary conditions are continuously chang-

Table 1

\begin{tabular}{|c|c|c|c|c|c|c|c|c|c|c|c|}
\hline \multirow[t]{2}{*}{ Material } & \multirow[t]{2}{*}{$E(\mathrm{GPa})$} & \multirow[t]{2}{*}{$v$} & \multicolumn{3}{|c|}{ Work-hardening (Swift law) } & \multicolumn{6}{|c|}{ Yield criteria (Hill'48) } \\
\hline & & & $Y_{\mathrm{o}}(\mathrm{MPa})$ & $K$ & $n$ & $F$ & $G$ & $H$ & $L$ & $M$ & $N$ \\
\hline DC06 & 210 & 0.3 & 123.6 & 529.5 & 0.268 & 0.26350 & 0.28329 & 0.71671 & 1.5 & 1.5 & 1.27947 \\
\hline DP600 & 210 & 0.3 & 330.3 & 1093 & 0.187 & 0.51274 & 0.49751 & 0.50249 & 1.5 & 1.5 & 1.27292 \\
\hline
\end{tabular}

Materials properties of DC06 and DP600 steels [16] 
ing during the forming process, increasing the importance of a correct evaluation of the actual contact surface and the kind of contact that is established in each point of the deformable body. A master-slave algorithm is adopted, with the tools behaving as rigid bodies. The Coulomb's classical law models the friction contact problem between the rigid bodies (tools) and the deformable body (blank sheet). The problem of the contact with friction is treated by an augmented Lagrangian approach. The abovementioned fully implicit Newton-Raphson scheme is used to solve, in a single loop, all the problem non-linearities associated to the problem of contact with friction and the elastoplastic behaviour of the deformable body.

The classification of the simulations are as followed: DC denotes mild steel segment (DC06), DP denotes dual-phase steel segment (DP600); the first two digits succeeding the alphabets denote the orientation of the rolling direction in mild steel and the last two digits denote the orientation of the rolling direction in dual-phase steel, with respect to the weld-line. Two different combinations of anisotropic blank sheet segments were studied (DCDP0045 and DCDP4500) and compared with the formability of a mild steel-dual-phase steel tailor-welded blank admitting that both materials have isotropic properties (DCDP). Thus, the study provides an insight into the effect of anisotropy in the blank sheets and their rolling direction orientations on the formability of tailor-welded blanks.

\section{Results and discussion}

Moderate difference in the punch force evolution was observed when the orientation of the rolling direction of blank sheets is either $0^{\circ}$ or $45^{\circ}$ to the weld-line as illustrated in Fig. 4. The punch force increases linearly up to about $14 \mathrm{~mm}$ of punch displacement, beyond which the rate of increase in the punch force decreases. After reaching a depth of $25 \mathrm{~mm}$, the punch force starts reducing marginally, indicating the onset of large-scale plastic deformation. The sheet segments continue to flow plastically under decreasing punch force. Isotropic material combination (DCDP) requires lowest punch force and anisotropic material combination (DCDP0045) requires highest punch force. The intermediate punch force evolution in DCDP4500 case indicates the improved flow characteristics due to anisotropy when the orientation of rolling direction is $45^{\circ}$ in mild steel sheet segment.

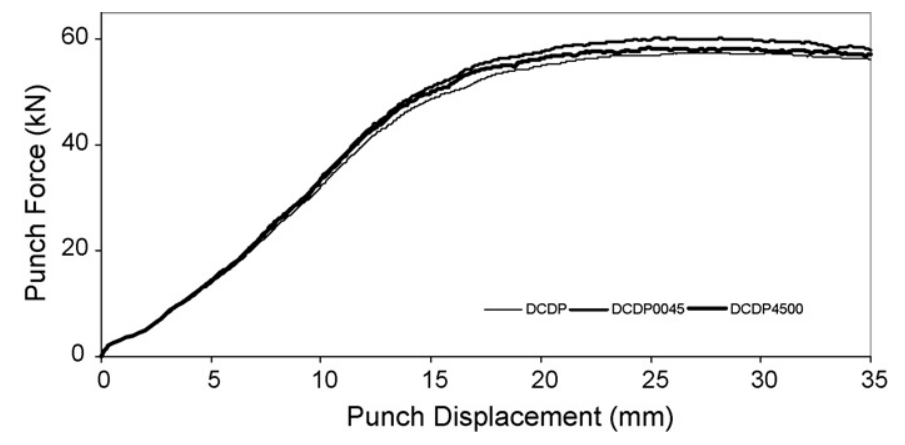

Fig. 4. Evolution of punch force on punch displacement.

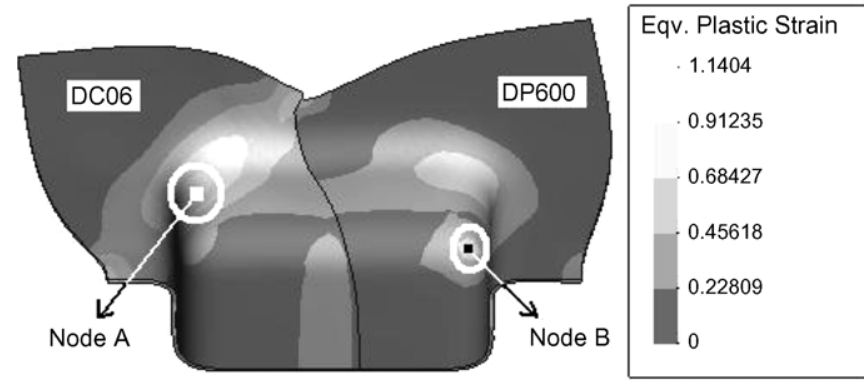

Fig. 5. Critical areas in the tailor-welded blank (e.g. equivalent plastic strain distribution).

Failure in deep drawn part usually occurs by thinning, therefore, it is important to identify the critical areas and determine the variation of strain in thickness direction during deformation $[29,30]$. Numerical simulations of the deep-drawing process indicate that the converging flow of the blank causes regions where the blank has a tendency to thickening as well as regions where the blank has a tendency to thinning. From the simulations, it is evident that near the rim, blank thickness tends to increase, whereas near the punch corners, the blank thickness tends to decrease causing potential tearing tendency. If the blank holder is fixed in space at a pre-set distance from the die, i.e. the initial thickness of the blank, it suppresses the tendency of the blank to thicken at its outer edge and thus induces a relatively high normal stress on the blank.

Consequently, the induced frictional shear stress resists the plastic flow and thus increases the tensile stress in the blank causing thinning at the punch corners. In the present set of simulations, a constant blank-holder force was applied on the blank sheets, to allow thickness variation. Strain localization at two critical locations occurred after deep-drawing all three tailorwelded blanks. One at the top corner of the cup in the mild steel sheet segment (Node A) and other at the bottom corner of the cup in dual-phase steel sheet segment (Node B), as shown in Fig. 5. Both critical locations occur along the diagonal direction in both steels. An important insight can be obtained by analysing the problem at these critical areas.

The two nodes (A and B), one in each area, were identified to represent these areas for stress-strain analysis over the entire deep-drawing process. Elements adjoining Node A, in DC06 steel segment, are subjected to complex stress state including tension along the cup diagonal and compression along the rim inducing large equivalent plastic deformation. Fig. 6 shows the plot with punch displacement on the abscissa and thickness strain on the ordinate in the critical area at Node A. The thickness strain was calculated from [29]:

$\varepsilon=\ln \left(\frac{t_{\mathrm{c}}}{t_{\mathrm{o}}}\right)$

where $t_{\mathrm{o}}$ and $t_{\mathrm{c}}$ are the initial and current thicknesses, respectively.

Though very high equivalent plastic deformation is prevalent in this area, this does not lead to failure. The thickness increases until about $20 \mathrm{~mm}$ of punch displacement and thereafter thinning occurs. The $45^{\circ}$ orientation of the blank sheet reduces thinning compared to the isotropic case and in particular to the $0^{\circ}$ ori- 


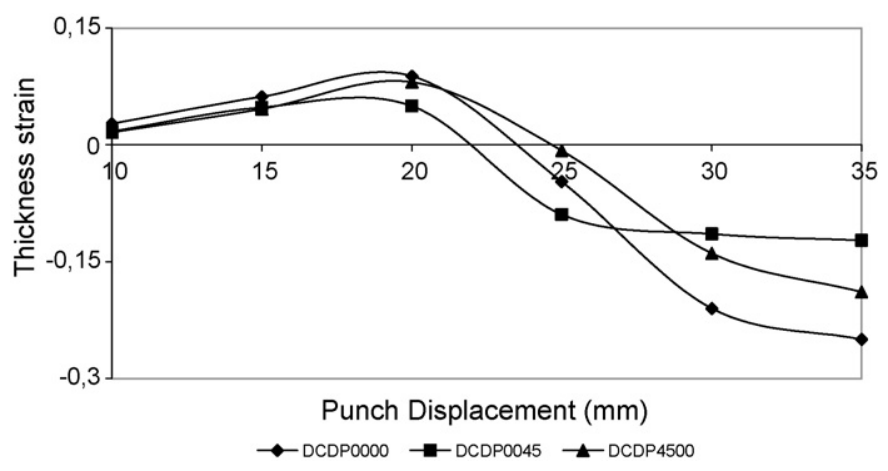

Fig. 6. Thickness strain evolution at Node A with punch displacement.

entation of the blank sheet. This is due to the high $r$-values of DC06 steel.

Fig. 7 shows the plot between thickness strain and punch displacement in the critical area at Node B in DP600 steel segment. Node B and the adjoining elements are subjected to biaxial stress state and consequently thinning occurs due to inadequate flow of material into this area. The difference in strains between $45^{\circ}$ and $0^{\circ}$ orientations of the blank sheet is small due to the low $r$-values of DP600 steel. It should be noted that the Hill' 48 yield function is known to inaccurately describe the behaviour of materials with low $r$-values [31]. In particular, it underestimates the biaxial state flow stress. Yet, the simulation results produced the trend in deformation behaviour of the tailor-welded blanks. In all the cases, the elements in this area do not reach a state of plastic instability within a draw depth of $35 \mathrm{~mm}$. Isotropic material combination undergoes more thickness straining compared to DCDP0045 and DCDP4500 combinations as shown in figure.

The main objective of any metal forming process is to minimize thinning. Simulation studies are important to predict the thickness distribution after forming; to minimize material failure by improving material flow. The flow of metal can be maximized through optimal blank-holder force and/or proper lubrication. In the present study, though the distribution of blank-holder force is uniform initially, its redistribution due to wrinkling tendency of the blank while draw-in induces non-uniformity in thickness during deformation. The blank-holder force is redistributed on the area of the blank where the thickness is increased, while the area where the thickness reduced experiences little blank-holder force. Fairly uniform distribution of thickness is observed in DCDP0045 and DCDP4500 tailor-welded blank models compared to isotropic tailor-welded blank case. Difference in the

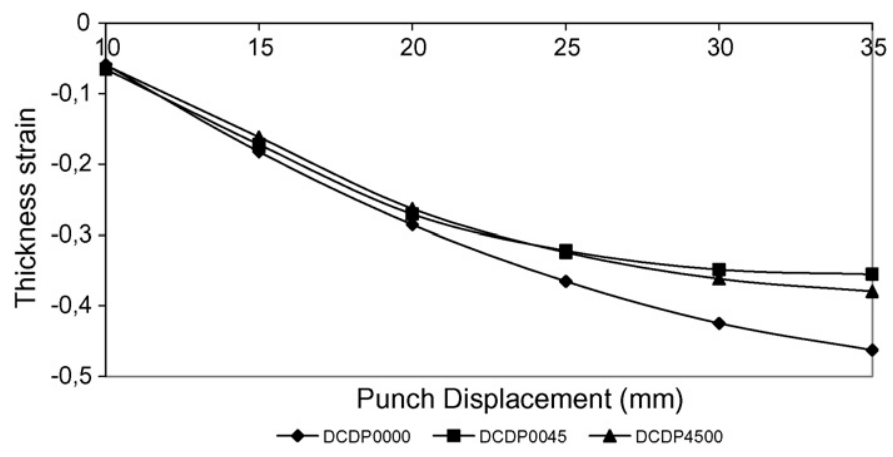

Fig. 7. Thickness strain evolution at Node B with punch displacement.

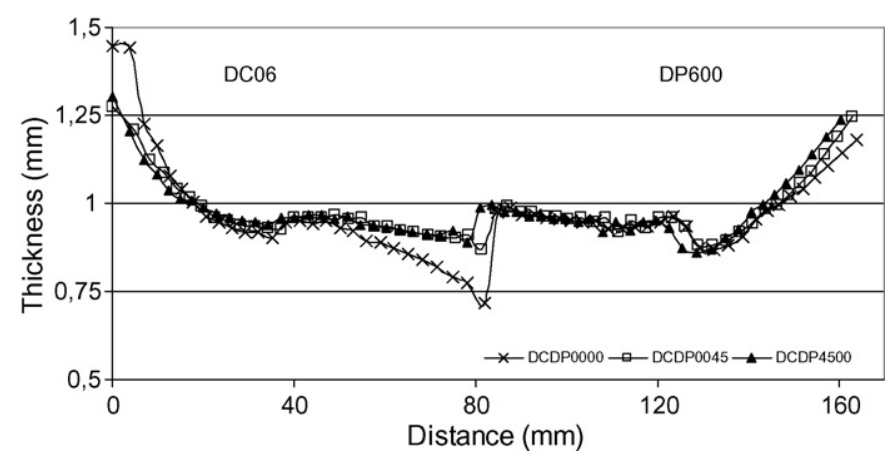

Fig. 8. Thickness variation along the symmetry line.

metal flow along the vertical walls and around the punch corners is typical of a square cup drawing. Consequent to this varied metal flow, mild thickness variation results in the deep drawn cup. Fig. 8 shows the thickness variation in the deep drawn cup along the symmetry line. Maximum thickness is observed at the flange and minimum thickness at the punch radius and along the weld-line. The mild steel segment is stretched farther than dualphase sheet segment leading to more thinning along the weldline on mild steel side. Isotropic combination of tailor-welded blank is subjected to maximum thinning along the weld-line. Influence of anisotropy is evident from the thickness variation in DCDP0045 and DCDP4500 combinations. Under certain combination of rolling direction orientation, formability of tailorwelded blanks improves the flow characteristics of the material and hence reduces thickness variation in the deep drawn cup.

As the deep-drawing of the tailor-welded blank proceeds, much of the stretching, and consequently large deformation is concentrated on the side of the blank with lower strength. The weaker material flows more at the drawn portion resulting in the weld-line displacement as shown in Fig. 9.

Comparatively larger deformation in the weaker material pushes the weld-line at the cup bottom towards stronger material. As a consequence, the flange of stronger material encapsulates the weaker material as indicated in the figure (also see Fig. 5). Isotropic mild steel segment is subjected to large localized deformation leading to large weld-line displacement towards dual-phase steel side. This tendency is greatly reduced upon introducing anisotropy in the blank sheets. The weld-line displacement also justifies the behaviour observed previously at nodes A and B (Figs. 6 and 7). For Node A, the higher strains

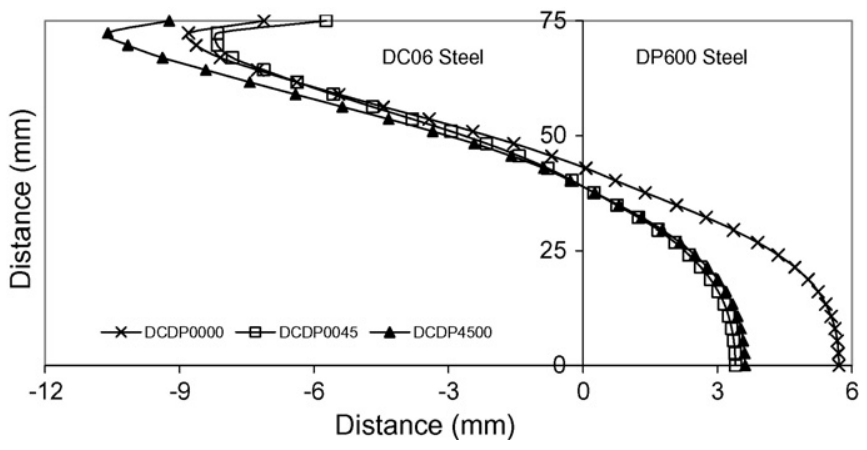

Fig. 9. Weld-line displacement after deep-drawing. 
results in the weld-line displacement on the flange towards DC06 steel side. For Node B, lower draw-in results in large weldline displacement in the isotropic case. Hence, high values of thinning are inevitable at the punch radius (Fig. 8).

\section{Conclusions}

Numerical simulations were carried out to determine the effect of anisotropy and the rolling direction orientation of the blank sheets in tailor-welded blanks to form a basis for tailorwelded blank development for a part. In-house finite element code DD3IMP was used for the deep-drawing simulation of a mild steel and dual-phase steel tailor-welded blank. The simulations were performed without considering the presence of a weld zone between DC06 and DP600 sheet segments in the tailorwelded blank. The results of anisotropic tailor-welded blanks are compared with isotropic tailor-welded blank. The punch force required for deep-drawing increases with anisotropy in the blank sheets. The strength difference and the initial anisotropy induce uneven metal flow during deep-drawing. The top corner of the cup in mild steel sheet segment is subjected to largest plastic strains and yet does not lead to material failure until a draw depth of $35 \mathrm{~mm}$ for this geometry. Inadequate material flow to the bottom cup corner on the dual-phase side causes thinning. The weak material is subjected to large deformation and hence, the weld-line moves towards the stronger material side in the cup section and towards the weaker material side in the flange area. Significant contribution by anisotropic property is observed on mild steel segment in the tailor-welded blank. Thinning along the weld-line is more in isotropic material combination than anisotropic tailor-welded blank. Using appropriate combination of rolling direction orientation, and hence controlling anisotropy, significant improvement in the formability of tailor-welded blanks can be achieved.

\section{Acknowledgement}

The authors are grateful to the Portuguese Foundation for Science and Technology (FCT) for the financial support for this work, through the Program POCI 2010.

\section{References}

[1] H. Kusuda, T. Takasago, F. Natsumi, Formability of tailored blanks, J. Mater. Process. Technol. 71 (1997) 134-140.

[2] E. Kubel, Manufacturers want more tailored blanks, Manuf. Eng. 119 (1997) 38-45.

[3] B. Kinsey, Z. Liu, J. Cao, A novel forming technology for tailor-welded blanks, J. Mater. Process. Technol. 99 (2000) 145-153.

[4] T. Meinders, A. van den Berg, J. Huetink, Deep-drawing simulations of Tailored Blanks and experimental verification, J. Mater. Process. Technol. 103 (2000) 65-73.

[5] R.J. Pallett, R.J. Lark, The use of tailored blanks in the manufacture of construction components, J. Mater. Process. Technol. 117 (2001) 249-254.

[6] M.A. Ahmetoglu, D. Brouwers, L. Shulkin, L. Taupin, G.L. Kinzel, T. Altan, Deep-drawing of round cups from tailor-welded blanks, J. Mater. Process. Technol. 53 (1995) 684-694.

[7] Y.M. Heo, S.H. Wang, H.Y. Kim, D.G. Seo, The effect of the drawbead dimensions on the weld-line movements in the deep-drawing of tailor-welded blanks, J. Mater. Process. Technol. 113 (2001) 686691.

[8] S.D. Raymond, P.M. Wild, C.J. Bayley, On modeling of the weld-line in finite element analyses of tailor-welded blank forming operations, J. Mater. Process. Technol. 147 (1) (2004) 28-33.

[9] L.P. Moreira, G. Ferron, G. Ferran, Experimental and numerical analysis of the cup drawing test for orthotropic metal sheets, J. Mater. Process. Technol. 108 (2000) 78-86.

[10] K.M. Zhao, B.K. Chun, J.K. Lee, Finite element analysis of tailor-welded blanks, Finite Elem. Anal. Des. 37 (2001) 117-130.

[11] B.Y. Ghoo, Y.T. Keum, Y.S. Kim, Evaluation of the mechanical properties of welded metal in tailored steel sheet welded by $\mathrm{CO}_{2}$ laser, J. Mater. Process. Technol. 113 (2001) 692-698.

[12] A. Makinouchi, E. Nakamachi, E. Onate, R.H. Wagoner (Eds.), Numisheet '93, Proceedings of the Second International Conference and Workshop on "Numerical simulations of 3-D Sheet Metal Forming Processes-Verification of Simulation With Experiments", Isehara, Japan, 31st August-2nd September, 1993.

[13] A.J. Baptista, D.M. Rodrigues, L.F. Menezes, Influence of the weld on the mechanical behaviour of tailor-welded blanks, Mater. Sci. Forum 514-516 (2006) 1493-1500.

[14] F.I. Saunders, R.H. Wagoner, Forming of tailor-welded blanks, Metall. Mater. Trans. A 27A (1996) 2605-2616.

[15] Y. Choi, Y. Heo, H.Y. Kim, D. Seo, Investigations of weld-line movements for the deep-drawing process of tailor-welded blanks, J. Mater. Process. Technol. 108 (2000) 1-7.

[16] Laboratoire des Propriétés Mécaniques et Thermodynamiques des Matériaux, "Selection and identification of elastoplastic models for the materials used in the benchmarks" in Progress Report of the Digital Die Design Systems (3DS) Project, University of Paris 13, 2001.

[17] GID-A Pre- and Postprocessor Reference Manual, Version 7, CIMNE, Barcelona, Spain.

[18] R. Hill, A theory of the yielding and plastic flow of anisotropic metals, in: Proceeding of the Royal Society, London A 193, 1948, pp. 281-297.

[19] F. Barlat, D.J. Lege, J.C. Brem, A six component yield function for anisotropic materials, Int. J. Plast. 7 (1991) 693-712.

[20] F. Barlat, H. Aretz, J.W. Yoon, M.E. Karabin, J.C. Brem, R.E. Dick, Linear transformation-based anisotropic yield functions, Int. J. Plast. 21 (2005) 1009-1039.

[21] A.P. Karafillis, M.C. Boyce, A general anisotropic yield criterion using bounds and a transformation weighting tensor, J. Mech. Phys. Solids 41 (1993) 1859-1886.

[22] D.C. Drucker, Relation of experiments to mathematical theories of plasticity, J. Appl. Mech. 16 (1949) 349-360.

[23] Y.S. Suh, F.I. Saunders, R.H. Wagoner, Anisotropic yield functions with plastic-strain-induced anisotropy, Int. J. Plast. 12 (3) (1996) 417-438.

[24] S. Bouvier, J.L. Alves, M.C. Oliveira, L.F. Menezes, Modelling of anisotropic work-hardening behaviour of metallic materials subjected to strain-path changes, Comput. Mater. Sci. 32 (2005) 301-315.

[25] O.S. Hooperstad, T. Berstad, H. Ilstad, O.G. Lademo, M. Langseth, Effects of the yield criterion on local deformations in numerical simulation of profile forming, J. Mater. Process. Technol. 80-81 (1998) 551-555.

[26] W.F. Hosford, Reflection on the dependence of plastic anisotropy on texture, Mater. Sci. Eng. A257 (1998) 1-8.

[27] P.D. Wu, M. Jain, J. Savoie, S.R. MacEwen, P. Tugcu, K.W. Neale, Evaluation of anisotropic yield functions for aluminum sheets, Int. J. Plast. 19 (2003) 121-138.

[28] L.F. Menezes, C. Teodosiu, Three-dimensional numerical simulation of the deep-drawing process using solid finite elements, J. Mater. Process. Technol. 97 (1-3) (2000) 100-106.

[29] D.W.A. Rees, Sheet orientation and formability limits under diffuse necking, Appl. Math. Modell. 20 (8) (1996) 624-635.

[30] D. Ravikumar, Formability analysis of extra-deep-drawing steel, J. Mater. Process. Technol. 130-131 (2002) 31-41.

[31] F. Barlat, Y. Maeda, K. Chung, M. Yanagawa, J.C. Brem, Y. Hayashida, D.J. Lege, K. Matsui, S.J. Murtha, S. Hattori, R.C. Becker, S. Makosey, Yield function development for aluminum alloy sheets, J. Mech. Phys. Solids 45 (11-12) (1997) 1727-2081. 